\title{
Seismic detection of rockslides at regional scale: examples from the Eastern Alps and feasibility of kurtosis-based event location
}

\author{
Florian Fuchs ${ }^{1}$, Wolfgang Lenhardt ${ }^{2}$, Götz Bokelmann ${ }^{1}$, and the AlpArray Working Group* \\ ${ }^{1}$ Department of Meteorology and Geophysics, University of Vienna, \\ Althanstraße 14, UZA 2, 1090 Vienna, Austria \\ ${ }^{2}$ Central Institute for Meteorology and Geodynamics, ZAMG, Vienna, Austria \\ * For further information regarding the team, please visit the link the end of the paper.
}

Correspondence: Florian Fuchs (florian.fuchs@univie.ac.at)

Received: 28 June 2018 - Discussion started: 10 July 2018

Revised: 19 September 2018 - Accepted: 16 October 2018 - Published: 29 October 2018

\begin{abstract}
Seismic records can provide detailed insight into the mechanisms of gravitational mass movements. Catastrophic events that generate long-period seismic radiation have been studied in detail, and monitoring systems have been developed for applications on a very local scale. Here we demonstrate that similar techniques can also be applied to regional seismic networks, which show great potential for real-time and large-scale monitoring and analysis of rockslide activity. This paper studies 19 moderate-sized to large rockslides in the Eastern Alps that were recorded by regional seismic networks within distances of a few tens of kilometers to more than $200 \mathrm{~km}$. We develop a simple and fully automatic processing chain that detects, locates, and classifies rockslides based on vertical-component seismic records. We show that a kurtosis-based onset picker is suitable to detect the very emergent onsets of rockslide signals and to locate the rockslides within a few kilometers from the true origin using a grid search and a 1-D seismic velocity model. Automatic discrimination between rockslides and local earthquakes is possible by a combination of characteristic parameters extracted from the seismic records, such as kurtosis or maximum-to-mean amplitude ratios. We attempt to relate the amplitude of the seismic records to the documented rockslide volume and reveal a potential power law in agreement with earlier studies. Since our approach is based on simplified methods we suggest and discuss how each step of the automatic processing could be expanded and improved to achieve more detailed results in the future.
\end{abstract}

\section{Introduction}

Gravitational mass movements shape the surface of our planet and pose sincere hazards to the human population, in particular in densely populated mountain regions such as the European Alps. Understanding the triggers of slope failures allows us to better evaluate their impact on the evolution of geomorphology and to design mitigation measures or early warning systems. However, such events may occur spontaneously and in remote areas and thus remain undetected in many cases. This can introduce significant uncertainty to, e.g., event inventories and triggering studies. Yet, comprehensive knowledge and reliable event data are of particular importance for the assessment of hazards imposed by rapid gravitational mass movements (Petschko et al., 2014; Lima et al., 2017). This renders remote and preferably real-time detection methods for rapid gravitational mass movements highly desirable. Classical approaches such as remote sensing via satellite imagery or stationary slope monitoring systems are usually limited in either temporal or spatial resolution and cannot cover vast areas in real time.

In recent years seismology has gained attention for being able to provide both temporal and spatial resolution for the detection and characterization or even forecasting of various kinds of mass movements. This includes land- 
slides (Helmstetter and Garambois, 2010; Feng, 2011; Moore et al., 2017), rockfalls (Hibert et al., 2011; Dammeier et al., 2016; Manconi et al., 2016; Gualtieri and Ekström, 2017), avalanches (Lacroix et al., 2012; van Herwijnen et al., 2016; Hammer et al., 2017), debris flows (Walter et al., 2017), and bed load transport (Schmandt et al., 2013; Burtin et al., 2016; Roth et al., 2017). Most of the studies that demonstrate the large potential of seismology for the event characterization of mass movements utilize long-period seismic radiation created by catastrophic landslides (Allstadt, 2013; Ekström and Stark, 2013; Hibert et al., 2014b). Seismic broadband observations of such events allow us to invert for the 3-D landslide force history and time-dependent center of mass position and - in combination with topography data - enable seismologists to fully describe a mass wasting event from remote (hundreds to thousands of kilometers of distance) observations. Such observations have revealed scaling laws that link seismic observables to the mass and momentum of massive landslides (Ekström and Stark, 2013), help to constrain numerical models of landslides (Moretti et al., 2012, 2015), and support observations of frictional weakening during sliding events (Lucas et al., 2014; Levy et al., 2015; Delannay et al., 2017).

Short-period seismic radiation generated by mass movements is more complex and challenging to interpret due to complex source mechanisms, the influence of topography, directional effects, and strong near-surface scattering and attenuation. Hibert et al. (2017b) report relations between the bulk momentum of catastrophic landslides and the $3-10 \mathrm{~Hz}$ bandpass-filtered envelopes of the respective seismic signals. At smaller scale, controlled experiments study the generation of high-frequency seismic waves by mass impact under field (Hibert et al., 2017a) or laboratory conditions (Farin et al., 2016). Only a few studies try to utilize high-frequency seismic waves to detect and characterize mass movements at local or regional scales. The majority of such studies rely on seismic data acquired in close proximity to the events, e.g., for monitoring of unstable slopes (Walter et al., 2012) or avalanches (van Herwijnen and Schweizer, 2011). Thus, although such approaches are powerful at small scale they are limited in spatial coverage (Burtin et al., 2013). Hibert et al. (2014b) demonstrate a robust automatic detection and location scheme for rockfalls inside a volcanic crater on $\mathrm{La}$ Réunion island. Deparis et al. (2008) first documented a set of rockfalls recorded by a regional seismic network in the Western Alps, and Dammeier et al. (2011) document statistical relations between rockfall characteristics and seismic recordings obtained from the Swiss permanent seismic network. Recently, there have been efforts to utilize existing regional seismic networks for the detection and characterization of mass movements (Dammeier et al., 2016; Manconi et al., 2016). Such networks, which were designed for earthquake monitoring purposes, usually consist of well-installed and sensitive seismic stations providing high-quality seismic data in real time and thus offer promising datasets, especially for the study of rockfalls and rockslides.

Here we present a study of 19 rockfalls and rockslides that occurred in or near Austria in the years 2007 to 2017 and were well recorded by permanent national seismic networks in the Alps during routine earthquake monitoring. We use this dataset of confirmed events to develop and test automatic detection and locating algorithms that could be used to systematically search for additional events in existing and future data. Exploring the feasibility of a country-wide real-time detection scheme for rockfalls, we focus on developing simple automatic location routines to automatically distinguish such events from regional earthquakes.

\section{Dataset}

This work is based on seismic recordings of 19 rockfall and rockslide events that occurred in Austria and the neighboring countries Switzerland and Italy during the years 20072017 (see Fig. 1 and Table 1). The event database was compiled by the Austrian earthquake service and focuses on rockslides and rockfalls from Austria and South Tyrol (Italy). These events were manually detected and classified during routine earthquake monitoring by the Austrian earthquake service (Central Institute for Meteorology and Geodynamics, ZAMG) and verified in cooperation with the Austrian Geological Service (GBA). We additionally include two largescale rockslides that occurred in Switzerland, but were also detected by the Austrian colleagues and assigned a magnitude. Out of these 19 events, 16 rockslides have been independently studied by field observations. All verified events were either first recognized by an analyst during routine national earthquake monitoring and later confirmed by field observations or were first recognized in the field and later clearly associated with seismic waveforms by analysts at ZAMG. For photographs of the individual events please follow the references listed at the end of the paper.

During routine processing of the seismic events, a local magnitude $M_{1}$ was assigned by ZAMG to all rockfalls and rockslides based on distance and maximum amplitude as read from the seismic records, just as if the events were earthquakes. The measured local magnitude ranges between 0.0 and 2.7. For all events ground-truth reference coordinates are available from field observations. However, other than the date and coordinates, few reliable event parameters are available since most of the events were not studied or mapped in detail on-site or because proper documentation could not be found.

We performed internet searches for all events listed in Table 1 to obtain on-site photographs and to find information on the volume of rock that was displaced. For almost all events we were able to retrieve the volume that was usually reported in local newspapers based on on-site estimates by local geological surveys. Note that these values might be sub- 


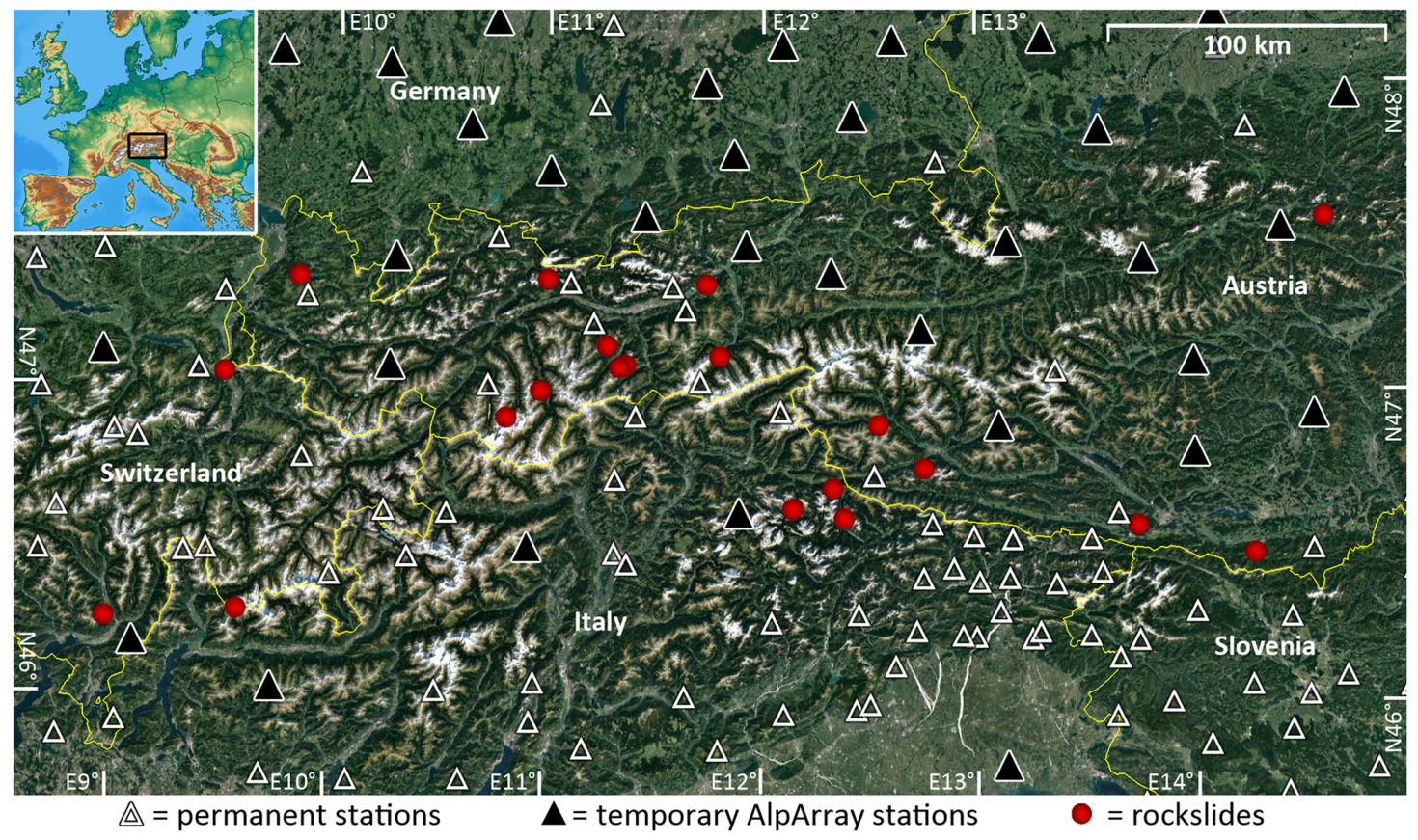

Figure 1. Map of the study area in eastern Austria and neighboring countries. Rockslides are marked by red circles. Bright and dark triangles denote permanent and temporary seismic stations, respectively. The yellow lines mark country borders. The inset marks the location of the study area in Europe.

ject to large uncertainties and should rather be considered as an order-of-magnitude estimation.

We obtained continuous waveform data for all 19 events from the European Integrated Data Archive (EIDA), which hosts data from the permanent broadband seismic stations in the Alps. For each rockfall we identified stations within a $300 \mathrm{~km}$ radius around the event and downloaded all available data for all three components (Z, N, E) and at the highest sampling rate available (see Fig. 1 for network geometry). All data since 2016 are provided at 100 sps sampling rate, while earlier data are partially only available at 25 sps. For events after 1 January 2016 we also used data from the temporary AlpArray broadband stations (100 sps), which covered the entire alpine region, and densify the seismic network, in particular in Austria (Fuchs et al., 2015, 2016; Hetenyi et al., 2018).

We use this dataset of confirmed rockslides to develop and test automatic detection and locating algorithms, which we describe in the following.

\section{Automatic processing}

The first step within the automatic processing chain is the identification of a rockfall event within the continuous background signal. We cut the seismic traces to 8 min segments around the known origin time ( $180 \mathrm{~s}$ prior to and $300 \mathrm{~s}$ after origin time) to simplify the processing and to avoid poten- tial false alarms at this stage of development. We also restrict our processing to the vertical component only. Prior to any further processing, we remove the instrument response, apply a $1-5 \mathrm{~Hz}$ bandpass filter, and taper and detrend the sliced data. Note that bandpass filtering is required to enhance the signal-to-noise ratio, especially to suppress microseism and long-period noise. Indeed, several earlier studies report this frequency band as dominant for regional seismic records of gravitational mass movements (Deparis et al., 2008; Dammeier et al., 2011; Manconi et al., 2016). Since many of the older waveform data are only available at $25 \mathrm{sps}$ sampling rate, we cannot reasonably extend the bandpass window to higher frequencies. For consistency we use the same settings even for 100 sps data.

\section{Event detection}

For simplicity we first implemented a recursive STA / LTA coincidence trigger to detect the rockfall signals (Trnkoczy, 2012). We used the following parameters for event detection: STA window, $5 \mathrm{~s}$; LTA window, $120 \mathrm{~s}$; trigger-on threshold ratio, 4.0; trigger-off ratio, 1.5; minimum number of stations, four. All events in our dataset created seismic waves strong enough to in principle be detected with the values stated above. Table 1 lists the number of stations with a positive STA / LTA trigger for each rockfall. The number of stations used for single event analysis in this study ranges from the minimum of four stations to more than 70 stations. The acti- 
Table 1. List of rockslides studied in this paper. Origin times are calculated from the seismic records. The coordinates denote the true location of the events obtained from field observations. The stations column denotes the number of stations that show a positive STA / LTA trigger. The distance column indicates the minimum and maximum distance from the events for these stations. Slide volumes were obtained from a web search and are usually based on local newspaper reports; please refer to the Acknowledgements section for source references. Events that are rockfalls rather than rockslides are marked with an asterisk $\left(^{*}\right)$. Local magnitude $M_{1}$ as estimated by the Austrian seismological service (ZAMG). The magnitude refers to the first event in the sequence. The volume estimates the total mass loss over all stages.

\begin{tabular}{|c|c|c|c|c|c|c|c|c|}
\hline Date & Time (UTC) & Name/town, country & Latitude & Longitude & Stations $^{\mathrm{a}}$ & Dist./km & Volume $/\left(10^{3} \times \mathrm{m}^{3}\right)$ & $M_{1}$ \\
\hline $2007-10-12$ & 07:39:24 & Einserkofel, IT & 46.6390 & 12.3483 & 9 & 80-196 & $60^{1}$ & 2.0 \\
\hline 2011-05-06 & $05: 22: 10$ & Kalkkögel, AT* & 47.1494 & 11.2736 & 5 & $30-106$ & $1^{2}$ & 0.9 \\
\hline 2011-10-23 & $14: 44: 34$ & Tscheppaschlucht, AT & 46.4995 & 14.2769 & 12 & $20-72$ & $30^{3}$ & 0.7 \\
\hline $2011-12-27$ & $17: 25: 43$ & Piz Cengalo, $\mathrm{CH}$ & 46.2950 & 9.6020 & 74 & $23-320$ & $1000-2000^{4,5}$ & 2.7 \\
\hline $2012-03-22$ & $22: 53: 24$ & Hochwand, AT & 47.3535 & 11.0041 & 24 & $23-207$ & $150^{6}$ & 1.4 \\
\hline $2012-05-01$ & $18: 26: 46$ & Gamsgrube, AT & 47.1179 & 11.7992 & 15 & $20-150$ & $1-10^{7}$ & 1.4 \\
\hline $2012-05-15$ & $02: 45: 38$ & Preonzo, $\mathrm{CH}$ & 46.2516 & 8.9846 & 56 & $33-235$ & $210^{8}$ & 2.2 \\
\hline $2012-05-29$ & 06:00:30 & Taschachtal, AT & 46.9186 & 10.8198 & 4 & $13-63$ & $150^{9}$ & 0.0 \\
\hline $2012-11-25$ & 11:29:04 & Regitzer Spitz, $\mathrm{CH}^{*}$ & 47.0405 & 9.5012 & 6 & $8-42$ & $0.18^{10}$ & 1.0 \\
\hline 2014-07-13 & 09:34:21 & Lienzer Dolomiten, AT & $-^{\mathrm{b}}$ & - & 6 & - & - & 0.4 \\
\hline $2014-11-24$ & $16: 27: 20$ & Trins, AT & $-^{\mathrm{b}}$ & - & 18 & - & - & 1.5 \\
\hline $2014-11-25$ & $02: 48: 39$ & Stubaital, AT & $-^{b}$ & - & 4 & - & - & 0.7 \\
\hline $2015-01-16$ & $19: 22: 50$ & Dobratsch, AT & 46.5914 & 13.7326 & 6 & $21-77$ & $6^{11}$ & 1.0 \\
\hline $2015-09-30$ & $20: 38: 18$ & Schwaz, AT & 47.3485 & 1.7427 & - & - & $0.5^{12}$ & 0.0 \\
\hline $2015-10-02$ & $15: 58: 56$ & Sölden, AT & 47.0051 & 10.9728 & 5 & $17-121$ & $100-200^{13}$ & 1.2 \\
\hline $2016-03-25$ & 17:14:03 & Mellental, AT & 47.3480 & 9.8400 & 45 & $7-176$ & $>250^{\mathrm{c} 14}$ & 1.9 \\
\hline $2016-05-25$ & $12: 51: 15$ & Gesäuse, AT & 47.5671 & 14.6203 & 6 & $17-70$ & $18^{15}$ & 1.1 \\
\hline 2016-08-19 & 21:57:04 & Kleine Gaisl, IT & 46.6425 & 12.1388 & 46 & $20-168$ & $600-700^{17}$ & 1.8 \\
\hline $2017-02-21$ & 09:36:35 & Zwölferkofel, IT & 46.6149 & 12.3749 & 40 & - & - & - \\
\hline
\end{tabular}

${ }^{\mathrm{a}}$ For an STA / LTA threshold of 4.0 (see Sect. 3 ); ${ }^{\mathrm{b}}$ not independently verified, no reference coordinates available; ${ }^{\mathrm{c}}$ the Mellental event occurred in three stages.

vation time of the STA / LTA trigger also serves as the initial signal onset time for further processing.

\section{Kurtosis onset picker}

Once our algorithm identified stations with a detectable seismic rockfall signal via the STA / LTA coincidence trigger it automatically determines the signal onset at each station. Unlike earthquakes, rockfalls and rockslides commonly show rather emergent signal onsets and hence we cannot use the STA / LTA trigger times as event starting times because the trigger-on threshold is always reached after the signal onset. Since Hibert et al. (2014a) successfully demonstrated the applicability to rockfall signals, we implemented a kurtosisbased phase picker to determine the onset of the emergent rockfall signals. The kurtosis is a statistical value, in this case characterizing the shape of a given amplitude distribution. It is a positive scalar defined as the standardized fourth moment about the mean. In discrete form it is written as

$$
\beta=\frac{\frac{1}{n} \sum_{i=1}^{n+1}\left(x_{i}-\bar{x}\right)^{4}}{\left(\frac{1}{n} \sum_{i=1}^{n+1}\left(x_{i}-\bar{x}\right)^{2}\right)^{2}},
$$

where $n$ is the total number of samples, $x_{i}$ the value of the $i$ th sample, and $\bar{x}$ the mean over $n$ samples. The kurtosis of a normal distribution is $\beta=3$ and any deviations from this value (i.e., excess kurtosis) can be used for the detection of potential seismic signals on top of regular background noise.

Similar to the processing described in Baillard et al. (2014) and Hibert et al. (2014a), we calculate a characteristic function $\mathrm{CF}(t)$ of the seismic signal $s(t)$ within a sliding window of size $\Delta T$.

$\mathrm{CF}(t)=\beta[s(t-\Delta T), \ldots, s(t)]$

The time window is set to $\Delta T=5 \mathrm{~s}$ and $t$ slides between $10 \mathrm{~s}$ before and $1 \mathrm{~s}$ after the preliminary onset time determined by the STA / LTA trigger. $\mathrm{CF}(t)$ has a maximum near the true signal onset, when the kurtosis $\beta$ of the seismic amplitude distribution within the sliding window $\Delta T$ is maximized; that is, when the entire time window is dominated by seismic signals from the event (see Fig. 2). However, for location purposes we are interested in the very first onset of the seismic signal, which is the first time $t$ at which the characteristic function $\mathrm{CF}(t)$ starts to deviate from the background level. Thus, we adopt the procedure of Hibert et al. (2014a) and modify $\mathrm{CF}(t)$ as follows. 


$$
\begin{aligned}
& \operatorname{cCF}(k)=\sum_{i=1}^{k} \alpha_{i} \\
& \text { with } \begin{cases}\alpha_{i}=\mathrm{CF}_{i+1}-\mathrm{CF}_{i} & \text { if }\left(\mathrm{CF}_{i+1}-\mathrm{CF}_{i}\right) \geq 0 \\
\alpha_{i}=0 & \text { otherwise }\end{cases}
\end{aligned}
$$

The function CCF can be read as the cumulative sum of the slope of $\mathrm{CF}$, and its value increases most drastically at the time of the signal onset. Thus, we define the time $t$ at which the time derivative $d(\mathrm{cCF}) / d t$ is maximized as the final signal onset time. If several maxima of $d(\mathrm{cCF}) / d t$ lie close to each other we define the first one as the signal onset time (see Fig. 2).

\section{Origin time and event location}

Figure 3 shows seismic record sections for two large-scale rockslides in different areas of the Eastern Alps with patterns of distinct seismic phase arrivals, which are common for most of the rockslides in this study. Despite the emergent character of the rockslide signals we can identify a first arrival that travels with an apparent velocity of approximately $5.0 \mathrm{~km} \mathrm{~s}^{-1}$. We thus assume that this arrival is a $\mathrm{P}$ wave. For eight events (Einserkofel, Hochwand, Gamsgrube, Trins, Stubaital, Dobratsch, Mellental, Zwölferkofel) a distinct second arrival is visible, which is usually stronger than the first arrival and sometimes (in the case of a low signal-to-noise ratio) is the only visible signal. This arrival travels with an apparent velocity of approximately $3.0 \mathrm{~km} \mathrm{~s}^{-1}$ and we suggest that it is due to $S$ waves or surface waves (see Discussion section). We exclude the possibility that the two distinct arrivals reflect two separate events, since with increasing distance we observe increasing separation time. In addition, no such separation is visible on the records of the stations closest to the rockslide.

We run a grid search to estimate the origin time and location of the rockslides based on the onset times determined by the kurtosis picker. The search area is a rectangle with $5 \mathrm{~km}$ grid spacing spanned by all seismic stations with positive STA / LTA detection. Time is scanned in steps of $2 \mathrm{~s}$ between the earliest measured onset time (latest possible origin time) and an estimated earliest possible origin time that is set as the first onset pick minus the maximum travel time along the grid diagonal. For each grid point and each time step we calculate the theoretical arrival time (fixed velocity of $5.0 \mathrm{~km} \mathrm{~s}^{-1}$, no topography) for all stations and its difference (residual) to the measured onset time. The grid point and time at which the root mean square (RMS) value of the set of station residuals is minimized is set as the preliminary origin time and event location (see Fig. 4). For one-third of the rockslides analyzed within this study the simple grid search location is already quite satisfactory, with results that are significantly less than $10 \mathrm{~km}$ from the true rockslide location.
To overcome the simplifications of the grid search we subsequently perform an iterative location routine as is done for earthquakes using the HYPOCENTER code (Havskov and Ottemoller, 1999) and a simple 1-D velocity model suitable for the Eastern Alps (Hausmann et al., 2010). The kurtosisbased onset picks are treated as crustal $\mathrm{P}$ waves. The results are summarized in Table 2 and demonstrate that good location accuracy can be achieved with regional seismic networks even for emergent rockslide signals. Eight of 18 tested events were located less than $6 \mathrm{~km}$ from the true location. Four events could not be located due to a very low signalto-noise ratio or insufficient number of stations. We discuss possible limitations and reasons for outliers as well as the robustness of the results in the Discussion section.

\section{Discrimination from regional earthquakes}

A key aspect for automatic processing of seismic rockslide data is to distinguish such events from earthquakes and other potential sources of seismicity. Hibert et al. (2014a) suggest a set of parameters that are extracted from the seismic signal and are systematically different for earthquakes and rockslides. Here we explore if this simple concept that was successfully applied on a local scale can be extended to the regional scale.

For each rockslide signal on each available station we extract the following three parameters (see Fig. 5): (1) the kurtosis of the envelope of the entire signal (EnvKurto); (2) the ratio between maximum amplitude and mean amplitude (Max / Mean); and (3) the ratio of the duration (Inc / Dec) of the increasing signal flank (signal start to maximum amplitude) compared to the duration of the decreasing signal flank (maximum amplitude to signal end). The end time of the event is defined as the time at which the $2 \mathrm{~s}$ moving average of the signal envelope decayed to 1.1 times the pre-event levels. The pre-event amplitude is estimated as the mean amplitude within a $60 \mathrm{~s}$ window $5 \mathrm{~s}$ prior to the first signal onset.

We extract the same three parameters from a set of regional earthquake records in order to identify potential differences between rockslides and earthquakes. We downloaded data for 31 earthquakes $\left(M_{1}<3.5\right)$ within August 2015 and January 2016 that occurred in or near western Austria. Thus, the earthquakes occurred in the same area as the rockslides and induced similar levels of shaking (see Fig. S1 and Table S1 and the Supplement for details). The processing of the earthquake data was the same as for the rockslide data and we read the parameters described above for each earthquake at each available station.

Figure 5 shows the distribution of potential discrimination parameters extracted from rockslides and earthquakes. For all parameters both distributions overlap but they peak at different values. Notably, for rockslides all values measured for the kurtosis of the envelope (EnvKurto) and the ratio of maximum to mean amplitude (Max / Mean) stay below a certain threshold compared to earthquakes. We make use of this ob- 

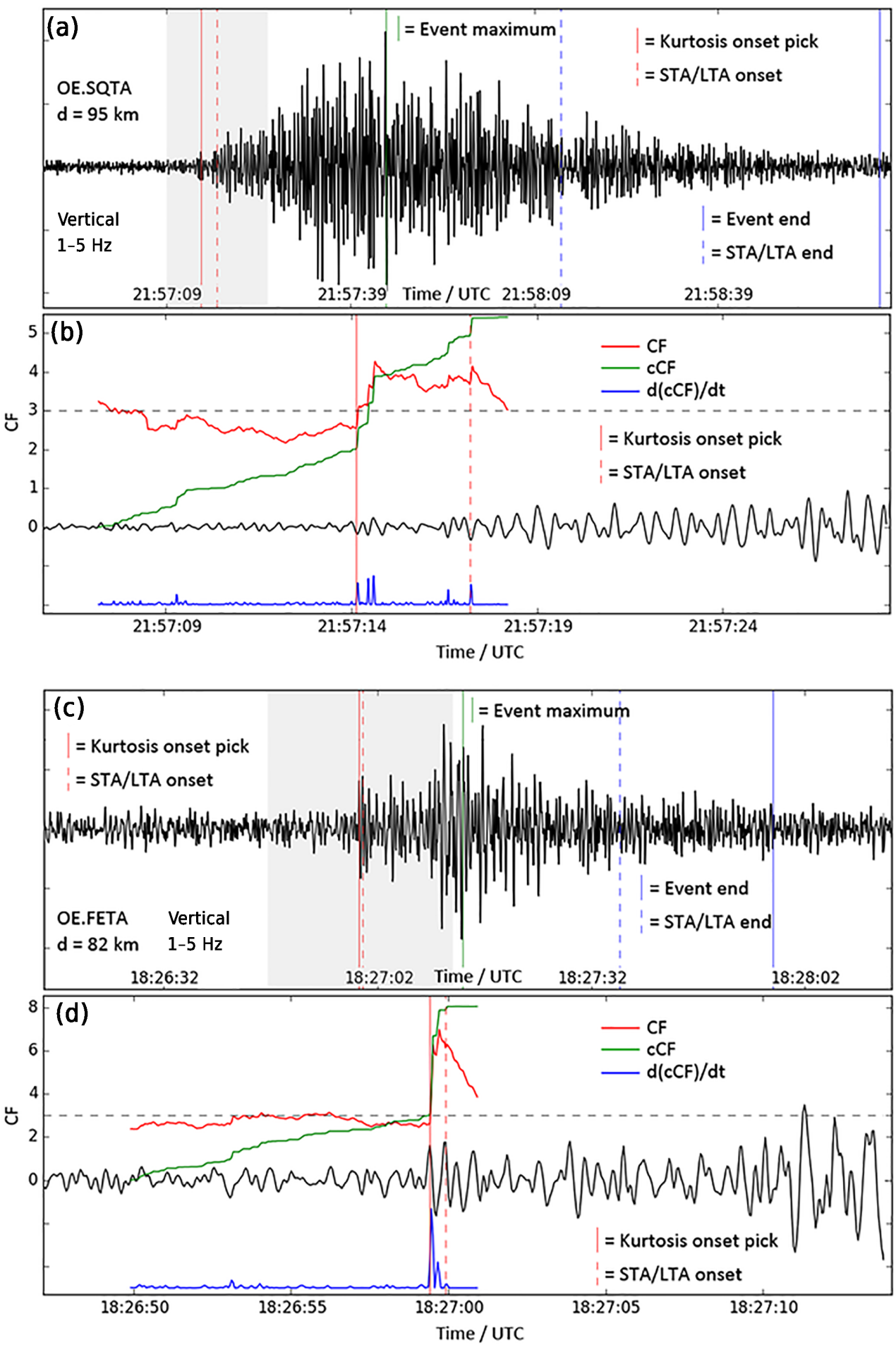

Figure 2. Examples for the performance of the kurtosis picker. All waveforms are from 1-5 Hz bandpass-filtered vertical components. Panels (a) and (b) show an example of the 19 August 2016, Kleine Gaisl, Italy, rockslide from station OE.SQTA at $95 \mathrm{~km}$ of distance. Panels (c) and (d) show an example of the 1 May 2012, Gamsgrube, Austria, rockslide from station OE.FETA at $82 \mathrm{~km}$ of distance. Panels (b) and (d) show close-ups of the grey-shaded parts of the waveforms in (a) and (c), respectively. The vertical axes in (b) and (d) indicate the values of $\mathrm{CF}$. For perfectly Gaussian noise we expect a value $\mathrm{CF}=3.0$, which is marked by the dashed horizontal lines. Vertical lines denote picks for the event onset and end. Solid red line: onset pick based on maximum $d(\mathrm{cCF}) / d t$. Dashed red line: onset time of STA / LTA trigger. Solid blue line: event end time as given by the 1.1 times the pre-event noise condition (see Sect. 3). Dashed blue line: end time of STA / LTA trigger (for comparison; not used for any processing). 
Table 2. Location quality based on kurtosis picks. The deviation indicates the discrepancy between the final location result and the true location of the event. Four events could not be located due to an insufficient number of picks.

\begin{tabular}{lclrrr}
\hline Date & Time (UTC) & Name/town, country & Stations $^{\mathrm{a}}$ & Azimuthal gap/ $^{\circ}$ & Deviation/km $^{\text {2015 }}$ \\
\hline $2012-05-15$ & $02: 45: 38$ & Preonzo, CH & 56 & 54 & 0.7 \\
$2015-01-16$ & $19: 22: 50$ & Dobratsch, AT & 5 & 273 & 3.7 \\
$2015-10-02$ & $15: 58: 56$ & Sölden, AT & 5 & 183 & 4.3 \\
$2016-08-19$ & $21: 57: 04$ & Kleine Gaisl, IT & 44 & 41 & 4.3 \\
$2012-05-01$ & $18: 26: 46$ & Gamsgrube, AT & 12 & 147 & 4.8 \\
$2016-03-25$ & $17: 14: 03$ & Mellental, AT & 40 & 64 & 5.0 \\
$2011-10-23$ & $14: 44: 34$ & Tscheppaschlucht, AT & 9 & 153 & 5.6 \\
$2012-11-25$ & $11: 29: 04$ & Regitzer Spitz, CH & 4 & 141 & 5.8 \\
$2011-12-27$ & $17: 25: 43$ & Piz Cengalo, CH & 73 & 87 & 8.3 \\
$2012-03-22$ & $22: 53: 24$ & Hochwand, AT & 27 & 175 & 8.3 \\
$2007-10-12$ & $07: 39: 24$ & Einserkofel, IT & 9 & 145 & 8.8 \\
$2011-05-06$ & $05: 22: 10$ & Kalkkögel, AT & 4 & 187 & 11 \\
$2016-05-25$ & $12: 51: 15$ & Gesäuse, AT & 5 & 206 & 16 \\
$2014-11-24$ & $16: 27: 20$ & Trins, AT & 18 & 134 & 26 \\
\hline $2012-05-29$ & $06: 00: 30$ & Taschachtal, AT & - & - & - \\
$2014-07-13$ & $09: 34: 21$ & Lienzer Dolomiten, AT & - & - & - \\
$2014-11-25$ & $02: 48: 39$ & Stubaital, AT & - & - & - \\
$2015-09-30$ & $20: 38: 18$ & Schwaz, AT & - & - & - \\
\hline
\end{tabular}

${ }^{a}$ Number of stations (number of picks) used for location routine; this number may deviate from the number of stations that passed the STA / LTA trigger (see Table 1) because the kurtosis algorithm may not have found viable onset picks. ${ }^{b}$ Only the strongest event from the sequence is listed.
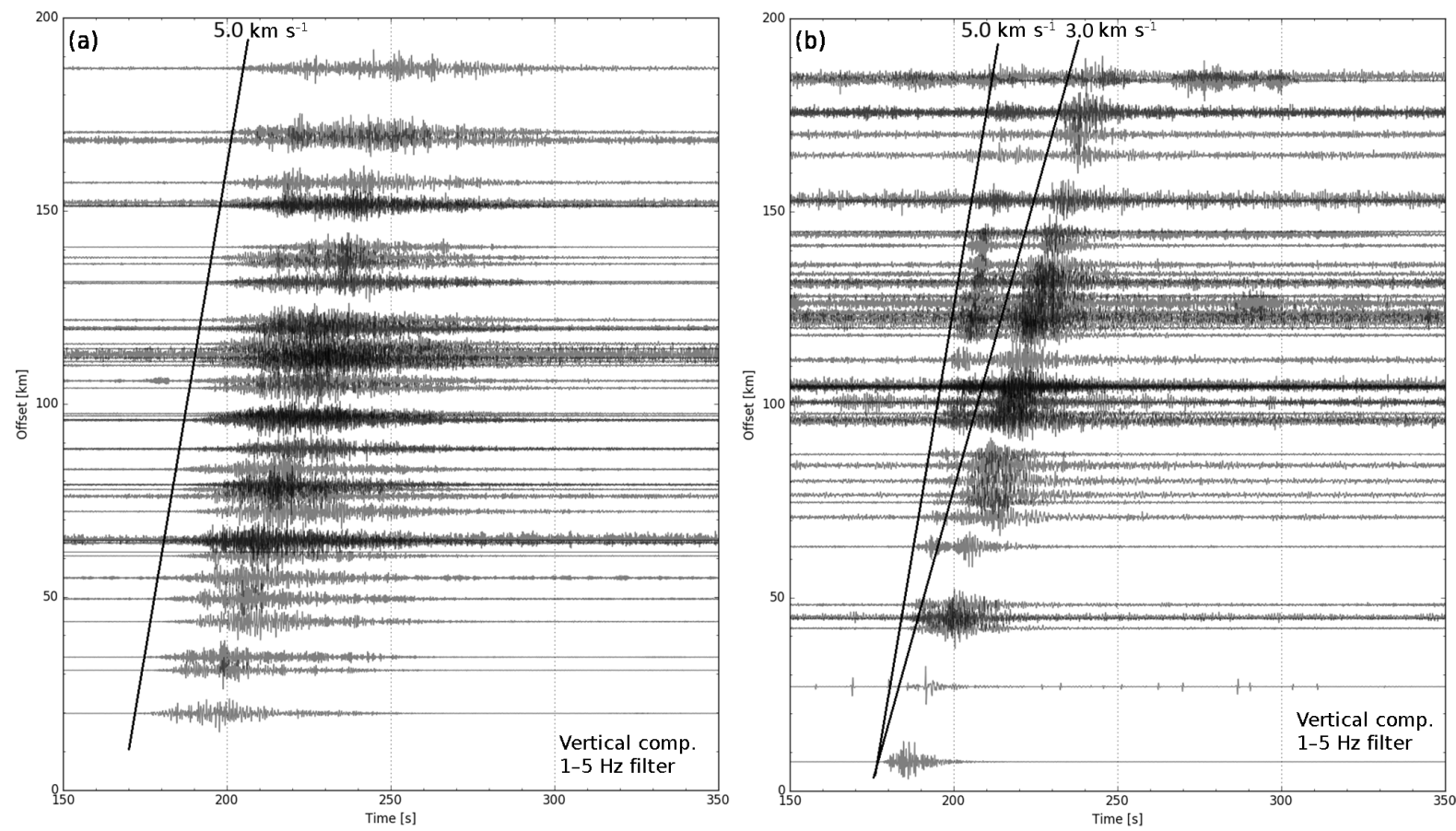

Figure 3. Record sections (signal vs. distance) of the vertical component for two large rockslides. All data are bandpass-filtered between 1 and 5 Hz. (a) Kleine Gaisl, Italy, 19 August 2016, is an event example that does not show a clear second arrival. (b) Mellental, Austria, 25 March 2016, does show a distinct second arrival for stations farther than $50 \mathrm{~km}$ from the origin. Black lines mark expected arrival times for a constant travel time of 5.0 and $3.0 \mathrm{~km} \mathrm{~s}^{-1}$, respectively. 


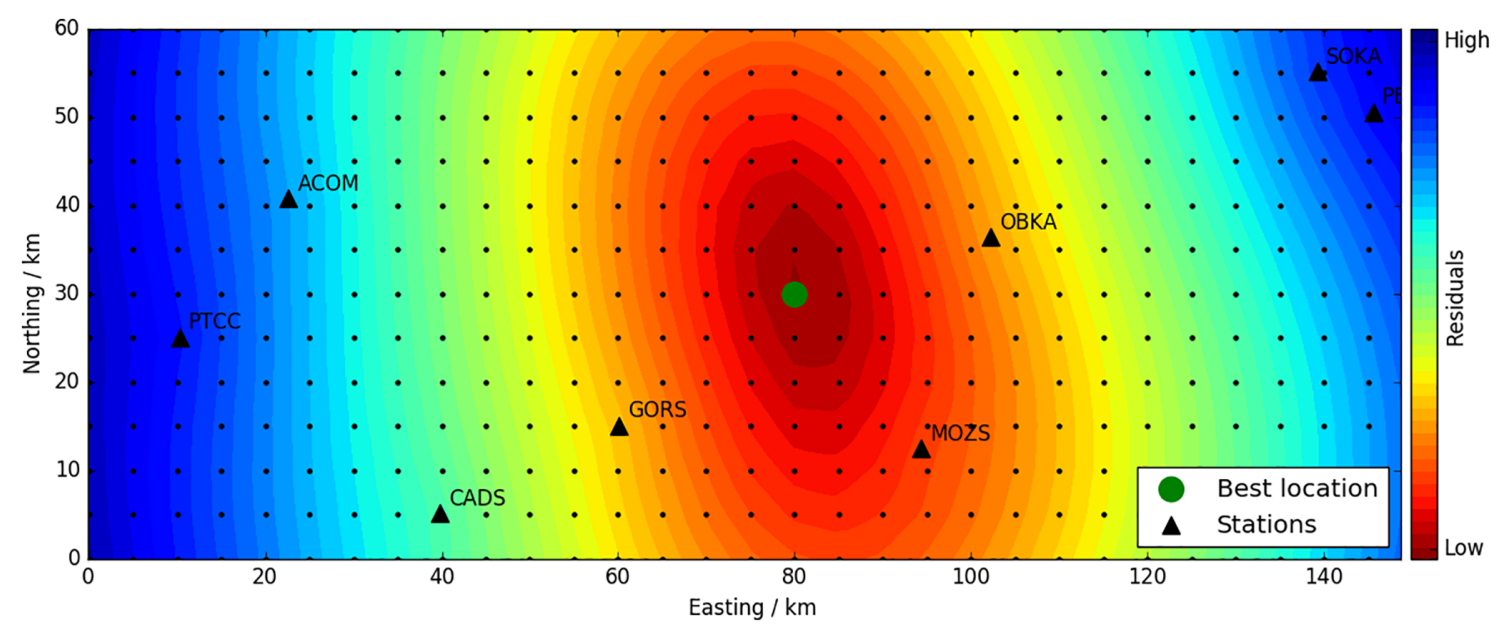

Figure 4. Example for a grid search result (rockfall in Tscheppaschlucht, Austria, 23 October 2011). Black triangles mark the stations used for the grid search. Colors indicate the root mean square travel time residuals among all stations (for the best-fitting origin time and for a fixed velocity of $5.0 \mathrm{~km} \mathrm{~s}^{-1}$ ). Note that colors are smoothed between grid points (small black dots). The green dot represents the grid point that minimizes the set of travel time residuals and thus marks the preliminary location of the rockslide.

servation and define a simple decision criterion for whether an event should be declared as a rockslide or earthquake. An event is considered a rockslide if the mean value measured over all stations satisfies the following condition.

$\log ($ EnvKurto $)<1.2$ AND $\log ($ Max/Mean $)<1.2$

AND $\log ($ Inc/Dec $)>-1.1$

This way all 19 rockslides and all 31 regional earthquakes are correctly identified and we demonstrate that even on a regional scale it might be possible to distinguish rockslides from earthquakes based on a few simple criteria. We introduce potential extensions of this scheme in the Discussion section.

\section{Volume-magnitude relation}

Besides the event location the event volume is a crucial parameter for an assessment of a rockslide. Thus we attempt to relate the slide volume to the local magnitude $M_{1}$, a parameter that is routinely determined for seismic events by any seismological service. Several studies (Deparis et al., 2008; Dammeier et al., 2011; Ekström and Stark, 2013; Hibert et al., 2014a) attempt to relate the volume of mass movements to the measured seismic energy or amplitude. However, derived scaling relations are often only loosely constrained due to, e.g., a limited number of events, generally large scatter, or insufficient information about the event. From the 19 events studied here, 15 rockslides have a magnitude assigned by ZAMG and a volume estimate available (see Table 1). Figure 6 shows the local magnitude as a function of the event volume. Note that we exclude the data pair ( $M_{1}=0.0, V=150000$; Schwaz event) since the volume es- timate is likely wrong. Although the proposed fit is not well constrained $\left(R^{2}=0.60\right)$ due to large scatter and limited data points, the distribution suggests a linear relation between the local magnitude $M_{1}$ and the logarithmic volume $V$.

$M_{1}=-0.60+0.44 \log V$

Since the local magnitude $M_{1}=\log \left(A / A_{0}\right)$ is a logarithmic measure of the seismic amplitude $A$ this translates into a power-law relation between the seismic amplitude $A$ and the rockslide volume $V$, including a regional correction term $A_{0}$ that depends on the epicentral distance corrections applied during the calculation of $M_{1}$.

$A=A_{0}\left(0.25+V^{0.44}\right)$

\section{Discussion}

Here we demonstrated that regional seismic networks can be used to reliably detect moderate- to large-sized rockslides to distances up to more than $200 \mathrm{~km}$. Such seismic networks cover vast areas and record data continuously, and many networks provide data in real time. Thus, they allow for the regional monitoring of potentially catastrophic mass movements, and they additionally provide a temporal resolution that is unmatched by classical methods such as remote sensing. Here we suggest several processing steps to analyze the seismic signal generated by rockslides and show that simple concepts and easy-to-integrate tools already provide reasonable insight into the events. This demonstrates that even large datasets may be screened for rockslide data automatically. 

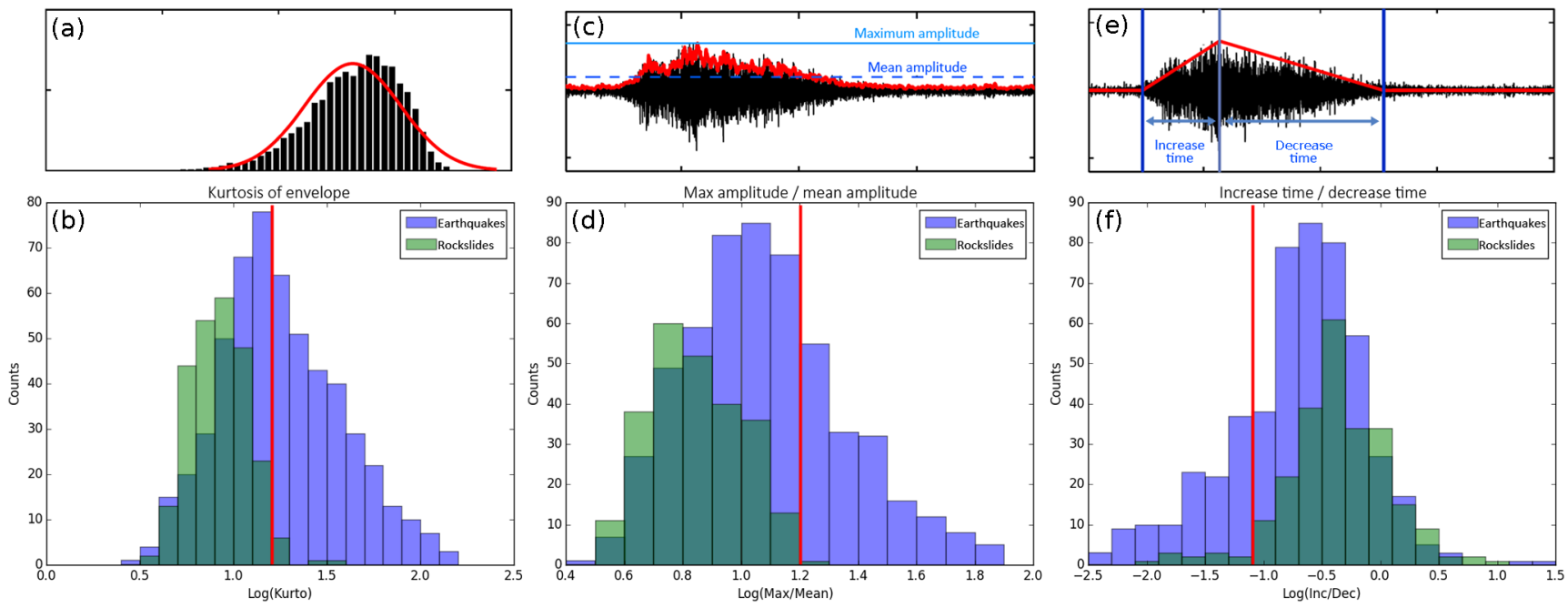

Figure 5. Distributions of the three different discrimination parameters for rockslides and earthquakes. Panels (a), (c), and (e) show the definition of the respective parameters. Panels (b), (d), and (f) show the frequentness of the respective parameters in logarithmic scale. Note that the total number of parameter reads is slightly higher for earthquakes than for rockslides and the distributions are not normalized. Green colors mark the values read from rockslide records, and blue colors mark the values read from earthquake records. The red lines in (b, $\mathbf{d}, \mathbf{f})$ mark the respective thresholds for the decision criterion (see Eq. 4).

While this shows the potential of regional seismic records to study gravitational mass movements, there is much room for improvement that may strongly increase the quality of the extractable information. All processing steps including the event location and characterization were performed completely automatically without the intervention of a human analyst. In particular, no attempt was made to remove outliers or, e.g., wrong onset picks, which in some cases greatly reduces the quality of the location result. Still, our simplistic approach may be complemented in most of the processing steps to increase the robustness of the results.

\section{Event detection}

We have shown that all moderate- to large-sized rockslides in this study could in principle be detected with an STA / LTA coincidence detector that is widely used by, e.g., seismological observatories and generally serves as a fast algorithm to screen datasets for events. However, STA / LTA detectors need to be balanced between sensitivity and the rate of false alarms. While the STA / LTA settings reported above safely detect all of our events we did not check how many false alarms would be introduced if a continuous data stream was analyzed (we cut the data to 8 min around the events). However, the STA / LTA triggering threshold level of 4.0 used in this study is commonly used for sites that are quiet on average (Trnkoczy, 2012). Increasing the number of stations needed for a positive result can in this case be used to lower the false alarm rate. Generally, there are more sensitive yet sometimes more computationally intensive algorithms to detect events in continuous seismic data. Dammeier et al.
(2016) demonstrate how alpine rockslides can be automatically detected on regional networks using hidden Markov models, which allows us to simultaneously detect and classify mass movements within seismic records. Manconi et al. (2016) report that the predictive multi-band detector FilterPicker (Lomax et al., 2012) is suitable to detect and phasepick emergent seismic signals of rockslides. Lassie is a stackand-delay-based coherence detector to find and locate events at the same time (Lopez Comino et al., 2017; Heimann et al., 2018) and may also be applicable to rockslide signals. Soubestre et al. (2018) demonstrate how coherent volcanic tremor signals can be detected and classified on a regional seismic network based on network covariance matrices. Since rockslide signals in several aspects resemble tremor signals (emergent onset, long duration, frequency content) this concept might also be applicable to rockslide detection. Template matching and subspace detectors (Maceira et al., 2010) are commonly used for earthquake and tremor detection, but we speculate that such methods may not be suitable for rockslide detection, as for every event waveforms are highly individual because of the complexity and variability in source mechanisms.

\section{Kurtosis picker performance and location accuracy}

Hibert et al. (2014a) designed a robust onset picker for rockslide signals based on a transition in the kurtosis. However, the method was only applied at a very local scale (network extension of a few kilometers) around a volcano. Baillard et al. (2014) also document the performance of a kurtosis picker for earthquake localization on regional seismic net- 


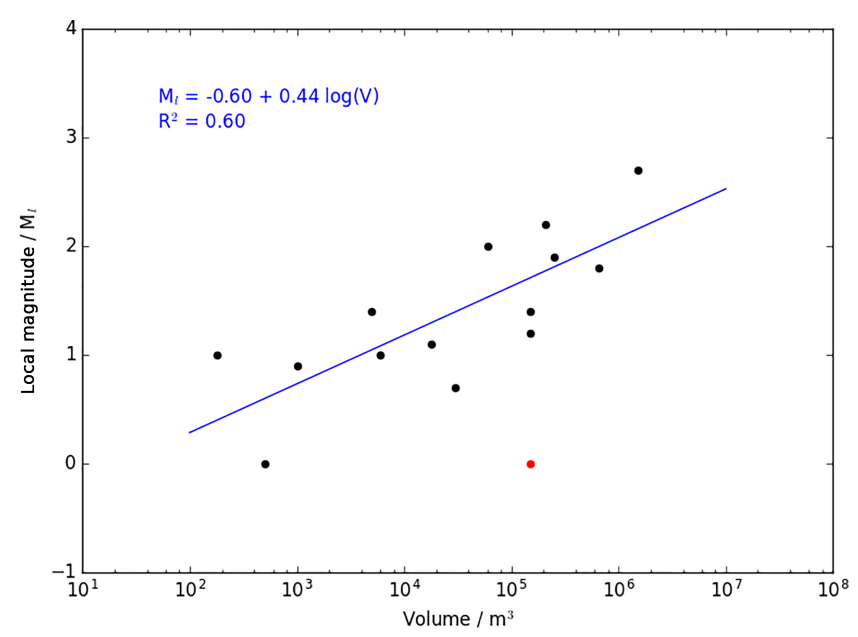

Figure 6. Local magnitude of all rockslides versus their volume (black dots). The distribution indicates a linear relation (blue line) between magnitude and logarithmic volume. The equation with the best-fitting parameters and the coefficient of determination $R^{2}$ are indicated above the graph. The data pair $\left(M_{1}=0.0\right.$, $V=150000 \mathrm{~m}^{3}$; marked red) is likely an outlier due to wrong volume estimate. We thus excluded this point from the linear fit.

works. Here we show that this concept could also be applied to the rather emergent signals induced by gravitational mass movements at regional distances. Eight of 14 locatable events in this study could be located within a few kilometers of deviation from the true location (see Table 1), which shows that based on onset picks a similar precision as for earthquakes is possible. However, some of the locations should be considered lucky hits, as the number of stations is low and the azimuthal gap is large, strikingly for some of the most welllocated events. We do in fact observe that the location results currently lack robustness and may change by a few kilometers when certain parameters of the kurtosis picker (e.g., the length of the moving window, bandpass filter corner frequencies) are adjusted. This is most likely due to both unfavorable noise conditions and to the simplistic processing we used for demonstration purposes. Additionally, we did not implement automatic outlier handling at this stage. Several of the bad locations listed in Table 2 can be explained by strong outliers in the kurtosis picks due to noise. We expect that picking accuracy can be greatly improved if measures are taken to make the kurtosis picker more robust and to exclude outliers. Future work should include all three components of the seismic record and use different narrow frequency bands for comparison, as suggested by Hibert et al. (2014a). We expect that evaluating the kurtosis pick among different frequency bands would suppress outliers (due to noise) and thus make the onset determination more robust and precise. Yet, in this study - due to low sampling rate for older records - we could not extend the processing to higher frequencies. Lower frequencies are very weak in amplitude or absent for almost all rockslides in this study. This is in line with observations from several other studies that report the $1-5 \mathrm{~Hz}$ frequency range as the dominant one for regional seismic records of rockslides (Deparis et al., 2008; Dammeier et al., 2011; Manconi et al., 2016).

Besides kurtosis methods, pickers based on, e.g., autoregressive prediction (Küperkoch et al., 2012) might be very suitable for emergent onset picks, as they include frequency and phase information in addition to the amplitude (kurtosis pickers are only based on amplitudes). Since determining the onset of an emergent signal is anyways challenging, pickless location routines such as waveform correlation (Arrowsmith et al., 2016) should also be explored for mass movements. Manconi et al. (2016) suggest combining the location probabilities obtained from seismic waves with location probabilities based on terrain slopes to narrow down the potential source areas.

For location purposes we assumed the first onset of the rockslide signals to be a direct, i.e., crustal, $\mathrm{P}$ wave. The observed average phase velocity of the first arrival is approximately $5.0 \mathrm{~km} \mathrm{~s}^{-1}$ (see Fig. 3), which is similar to the observations by Dammeier et al. (2011) and represents a typical value for P-wave velocities in the upper crust of the Eastern Alps (Ye et al., 1995; Husen et al., 2003; Hausmann et al., 2010). For some events (Einserkofel, Hochwand, Gamsgrube, Trins, Stubaital, Dobratsch, Mellental, Zwölferkofel) a very distinct second arrival is visible (see Fig. 3b) that travels at lower velocities of approximately $3.0 \mathrm{~km} \mathrm{~s}^{-1}$. In this velocity range we potentially expect both crustal $\mathrm{S}$ waves and surface waves. If the type of wave was clearly identifiable a second phase pick would be available that could drastically increase the location accuracy. The majority of events (Fig. 3a) show no clear second onset and amplitudes gradually increase towards the maximum after the first onset. This cigar-type shape is more commonly found in other seismic studies of landslides and rockslides (Deparis et al., 2008; Dammeier et al., 2011; Hibert et al., 2014a). For such events we observe that the signal group around the maximum amplitude travels slower than the first onset, which suggests that $\mathrm{P}$ waves and other types of waves mix within the signal and complicate any in-detail analysis of the seismic phases or polarization. The mechanism of each individual rockslide event likely influences the relative strength at which certain wave types are generated. We also suggest that depending on the slide mechanism, e.g., $\mathrm{P}$ waves and $\mathrm{S}$ waves must not necessarily be excited at the same time during the event. Additionally, a rockslide is potentially a very directional source of seismic energy that may introduce anisotropic radiation patterns for the seismic energy. Wang et al. (2016) point out the influence of scattering at surface topography for location purposes and we should note that gravitational mass movements might be particularly affected by such effects since they occur in areas of pronounced topography and at the earth's surface. 


\section{Event discrimination}

We show that rockslides and earthquakes from the same source region can be discriminated by a few simple parameters such as the ratio between the maximum and mean amplitude of the seismic signal or the amplitude distribution. Manconi et al. (2016) present a robust decision criterion only based on the ratio $M_{1} / M_{\mathrm{d}}$ of the local magnitude $M_{1}$ and the duration magnitude $M_{\mathrm{d}}$. Hibert et al. (2014a) proposed combining several criteria within a simple fuzzy logic decision algorithm and we suggest that similar approaches can also safely distinguish rockslides from earthquakes on a regional scale. Note, however, that each region where such methods is applied might require individual modification of the decision thresholds for each parameter. Recently, more sophisticated decision algorithms based on machine learning have been developed that allow us to classify any kind of seismic event within a huge event database with great precision, after being trained by selected known events. Dammeier et al. (2016) demonstrate how a single training event can be used to scan continuous data for rockslides based on hidden Markov models. Classifiers based on random forest algorithms were successfully applied to classify gravitational mass movements and other events in several different settings, such as volcanoes (Maggi et al., 2017) and slow-moving landslides (Provost et al., 2017), and show great potential for application to regional seismic networks (Hibert et al., 2018). Random forest classifiers work more reliably the more training events are available. Recent studies demonstrate that sensitivities higher than $85 \%$ can be achieved if just $10 \%$ of the events inside a dataset are used to train the algorithm (Provost et al., 2017; Hibert et al., 2018). In the work of Provost et al. (2017) this corresponds to 20-40 training events per event category, which is the same order of magnitude as the number of events in this study, suggesting that these could be sufficient to screen larger datasets.

\section{Volume estimation}

Extracting reliable volume or mass information from seismic records of mass movement remains challenging and requires more research on the factors influencing the efficiency of seismic wave generation. Among these factors are the bulk mass, the drop mechanisms (free fall and impact versus sliding), the slope, and the runout distance. For the 19 events in this study we can only estimate the drop mechanism from photographs, which is not always conclusive. While the majority of events would classify as rockslides, some may include a free-fall phase and could rather be regarded as rockfalls (see Table 1). For catastrophic events that generate strong long-period signals, such properties can be inverted from the seismic data (Allstadt, 2013; Ekström and Stark, 2013; Hibert et al., 2014b). Short-period radiation is more complex to interpret, however. Hibert et al. (2017b) report simple scaling relations between the bulk mass mo- mentum and short-period seismic amplitudes for catastrophic landslides from within the same source area if source mechanisms are comparable among different events. They also report similar observations for controlled single-block fall experiments (Hibert et al., 2017a). At local scale, knowledge of the topography and a large number of events helps to constrain parameter estimates based on the seismic signals (Hibert et al., 2014a). At regional scale, however, unknown scattering, attenuation, and propagation of short-period seismic waves may obscure any potential scaling relations.

Deparis et al. (2008) point out that regional attenuation relations extracted from earthquakes may not be applicable to rockfall records and thus local magnitudes may not properly reflect the amount of seismic energy released by the source. They suggest that peak ground velocity is not a good measure to characterize rockfall signals. In contrast, Dammeier et al. (2011) deduct reasonably well-constrained relationships between rockslide parameters and the seismic peak ground velocity. This is in agreement with our findings that show an acceptable power-law relation between the averaged maximum seismic amplitude and the slide volume. Note, however, that apart from the volume estimate the local magnitude may not be very well defined, especially for low-magnitude $\left(M_{1}<2\right)$ events with only a few amplitude readings available. Dammeier et al. (2011) suggest that the regional propagation and attenuation of rockslide signals is strongly influenced by topography. In addition, several studies observe that seismic efficiency - the ratio of available potential energy over the released seismic energy - is usually low for gravitational mass movements (Deparis et al., 2008; Ekström and Stark, 2013; Hibert et al., 2014a). This may in part explain the poor correlations between seismic amplitudes and the rockslide volumes for several studies (including this one), since it suggests that a large part of the potential energy is released through other processes (e.g., friction, cracking, plastic deformation) and not transmitted seismically (Deparis et al., 2008). Manconi et al. (2016) attempt to derive a scaling law for rockslide volume not based on seismic amplitudes but on the duration magnitude $M_{\mathrm{d}}$, and they show a reasonable empirical correlation even for events of very different mechanisms and origin areas.

A general drawback of many studies (including this one) that aim to identify scaling relations for seismic energy created by gravitational mass movements at regional scale is the limited number of events (Deparis et al., 2008; Dammeier et al., 2011; Manconi et al., 2016). This is partly due to the limited availability of high-quality seismic data (network density, sampling rate), geographical restrictions (e.g., country borders), or lack of reliable event information (e.g., volume). Advancing our knowledge about short-period seismic radiation created by gravitational mass movements now calls for several actions: merging or cross-checking national event databases, which unfortunately often end at country borders, should greatly improve the number of events available for analysis and the robustness of the event parameters. Multi- 
disciplinary approaches should also be explored to constrain event parameters routinely via, e.g., remote sensing. Finally, efficient data screening algorithms will allow us to detect and classify gravitational mass movements inside huge datasets, such as the AlpArray seismic network (Hetenyi et al., 2018). This will drastically increase the number of events to study and thus opens new possibilities to investigate the triggers and mechanisms of gravitational mass movements.

\section{Conclusions}

We have outlined simple methods on how to search for seismic signatures of rockslides in data from regional seismic networks up to more than $200 \mathrm{~km}$ from the origin. Kurtosisbased phase pickers allow us to reliably detect the onset of rockslide signals despite their emergent character. Resulting location accuracies are in the range of a few kilometers and can potentially be further reduced by incorporating proper handling of outliers and if secondary phases can be clearly associated. Automatic discrimination from earthquakes and other local or regional sources is possible by a simple combination of three decision parameters, such as maximum-tomean amplitude ratio. Based on a larger set of similar parameters, the future application of machine-learning techniques to data from regional seismic networks promises automatic event classification with great accuracy. This will likely increase the number of seismically detected rockslide events at regional scale. Larger and better parameterized datasets of rockslides will clarify scaling relations between event parameters and seismic observables and will help to better understand the seismic waves created by gravitational mass movements. Regional seismic networks can cover vast areas and at the same time provide continuous data for very long time series. This combination of spatial coverage and temporal resolution is currently unmatched by other geophysical methods. Thus, seismic networks are ideally suited to remotely study time-dependent rockslide activity. This may include long-term variations in rockslide activity potentially linked to climate change, fore- and after-slides of a main event, and more detailed insight into rockslide triggering factors.

Data availability. The majority of the seismic waveform data used in this study are openly available for download at the European Integrated Data Archive (EIDA; http://www.orfeus-eu.org/data/eida/ index.html, last access: October 2018). Waveform data with network code Z3 were acquired from the temporary AlpArray Seismic Network (AlpArray Seismic Network, 2015), which at the time of publication was not openly available according to the decision of the AlpArray Working Group. Please visit http://www.alparray.ethz. ch/en/seismic_network/backbone/data-access/ (last access: October 2018) for a complete description of data access.

All processing required for this paper was done using the $\mathrm{Ob}$ sPy toolbox (Krischer et al., 2015; The ObsPy Development Team, 2017). For location purposes we made use of certain modules of the SEISAN analysis software package (Havskov and Ottemoller, 1999).

Rockslide photographs and references for volume estimations in Table 1 are as follows (last access date for all links below: October 2018).

1. http://tirv1.orf.at/stories/228199

2. http://tirv1.orf.at/stories/514304

3. http://kaernten.orf.at/news/stories/2506673

4. www.srf.ch/play/tv/news-clip/video/ fast-unbemerkt-riesen-bergsturz-im-bergell?id= 6f9ce66d-6c9b-47c3-9842-5ee19531af57

5. http://www.zeit.de/2014/36/bergell-bergsturz-schweiz

6. Geoforum Tirol, Tagungsband, 14. Geoforum Umhausen, 2012

7. https://www.meinbezirk.at/telfs/lokales/heuer-bereitsvier-mal-soviele-einsaetze-wie-im-vergleich-zum-vorjahrd212155.html

8. Loew et al. (2017) (see below)

9. http://tirol.orf.at/news/stories/2535035

10. http://www.vilan24.ch/Flaesch.114.0.html?\&cHash= 0a607912512d9efae1fe768fb2a36494\&tx_ttnews\%5Btt_ news $\% 5 \mathrm{D}=7719$

11. https://www.zamg.ac.at/cms/de/geophysik/news/ massiver-felssturz-am-dobratsch-bei-villach

12. https://www.tirol.gv.at/meldungen/meldung/artikel/ ersteinschaetzung-der-landesgeologie-keine-gefahr-fuersiedlungsraum

13. http://www.tt.com/panorama/natur/10657382-91/\%C3\% B6tztaler-felssturz-kam-einem-erdbeben-gleich.csp

14. E. Vigl, https://backend.univie.ac.at/fileadmin/user_upload/i img/Geophyik/Aktenvermerk_Steinschlag_Mellental_E_Vigl. pdf

15. J. Reinmüller, https://backend.univie.ac.at/fileadmin/user_ upload/i_img/Geophyik/Dachl-Felssturz.pdf

16. http://www.tt.com/panorama/natur/11727492-91/ nach-felssturz-in-hopfgarten-land-baut-sicherheitsdamm.csp

17. https://www.unsertirol24.com/2016/08/20/ berg-stuerzt-in-prags-beeindruckende-bilder/

\section{The Supplement related to this article is available online at: https://doi.org/10.5194/esurf-6-955-2018-supplement}

Team list. The AlpArray Working Group: http://www.alparray. ethz.ch/en/seismic_network/backbone/data-policy-and-citation/ (last access: 25 October 2018). 
Author contributions. FF led the study, developed the codes, and wrote the paper. WL compiled the event list, provided event details, and analyzed individual events. GB supervised the study and helped compile the paper. The AlpArray Working Group jointly installed the seismic network Z3 and developed guidelines to ensure data quality.

Competing interests. The authors declare that they have no conflict of interest.

Special issue statement. This article is part of the special issue "From process to signal - advancing environmental seismology". It is a result of the EGU Galileo conference, Ohlstadt, Germany, 6-9 June 2017.

Acknowledgements. This work was funded by the Austrian Science Fund FWF project number P26391. This work benefited from fruitful discussions at the EGU Galileo conference on Environmental Seismology 2017, Ohlstadt, Germany.

We thank Helmut Hausmann (ZAMG) for his help in compiling the event parameters and independent information. Nils Tilch and Alexandra Haberler of the Geological Survey of Austria (GBA) are thanked for the cooperation and help in compiling the event database, verification of seismic data, and alerting us to new rockslides.

We acknowledge the use of data from the AlpArray network (code Z3; AlpArray Seismic Network, 2015); please visit the project home page at http://www.alparray.ethz.ch (last access: 25 October 2018) for a full list of people contributing to the AlpArray seismic network.

For this study we used seismic data from several permanent seismic networks and we appreciate the continuous operation of these seismic networks by the responsible institutions: BW net (Department of Earth and Environmental Sciences, Geophysical Observatory, University of Munchen, 2001), CH net (Swiss Seismological Service SED at ETH Zurich, 1983), CR net, FR net (RESIF, 1995), GN net (Institut de Physique du Globe de Paris IPGP \& Ecole et Observatoire des Sciences de la Terre de Strasbourg EOST, 1982), GU net (University of Genova, 1967), GR net, IV net (INGV Seismological Data Centre, 1997), MN net (MedNet project partner institutions, 1988), NI net (OGS Istituto Nazionale di Oceanografia e di Geofisica Sperimentale and University of Trieste, 2002), OE net, OX net (OGS Istituto Nazionale di Oceanografia e di Geofisica Sperimentale, 2016), SI net, SL net (Slovenian Environment Agency, 2001), and ST net (Geological Survey-Provincia Autonoma di Trento, 1981). We acknowledge ORFEUS and EIDA for providing the tools to access the seismic data.

Edited by: Michael Dietze

Reviewed by: Naomi Vouillamoz and one anonymous referee

\section{References}

Allstadt, K.: Extracting source characteristics and dynamics of the August 2010 Mount Meager landslide from broadband seismograms, J. Geophys. Res.-Earth, 118, 1472-1490, https://doi.org/10.1002/jgrf.20110, 2013.

AlpArray Seismic Network: AlpArray Seismic Network (AASN) temporary component, AlpArray Working Group, Datacite link: http://data.datacite.org/10.12686/alparray/z3_2015 (last access: 25 October 2018), Project webpage: http://www.alparray.ethz.ch (last access: 25 October 2018), https://doi.org/10.12686/alparray/z3_2015, 2015.

Arrowsmith, S., Young, C., Ballard, S., Slinkard, M., and Pankow, K.: Pickless Event Detection and Location The Waveform Correlation Event Detection System (WCEDS) Revisited, B. Seismol Soc. Am., 106, 2037-2044, https://doi.org/10.1785/0120160018, 2016.

Baillard, C., Crawford, W. C., Ballu, V., Hibert, C., and Mangeney, A.: An Automatic Kurtosis-Based P- and S-Phase Picker Designed for Local Seismic Networks, B. Seismol. Soc. Am., 104, 394-409, https://doi.org/10.1785/0120120347, 2014.

Burtin, A., Hovius, N., Milodowski, D. T., Chen, Y.-G., Wu, Y.-M., Lin, C.-W., Chen, H., Emberson, R., and Leu, P.-L.: Continuous catchment-scale monitoring of geomorphic processes with a 2D seismological array, J. Geophys. Res.-Earth, 118, 1956-1974, https://doi.org/10.1002/jgrf.20137, 2013.

Burtin, A., Hovius, N., and Turowski, J. M.: Seismic monitoring of torrential and fluvial processes, Earth Surf. Dynam., 4, 285-307, https://doi.org/10.5194/esurf-4-285-2016, 2016.

Dammeier, F., Moore, J. R., Haslinger, F., and Loew, S.: Characterization of alpine rockslides using statistical analysis of seismic signals, J. Geophys. Res., 116, F04024, https://doi.org/10.1029/2011JF002037, 2011.

Dammeier, F., Moore, J. R., Hammer, C., Haslinger, F., and Loew, S.: Automatic detection of alpine rockslides in continuous seismic data using hidden Markov models, J. Geophys. Res.-Earth, 121, 351-371, https://doi.org/10.1002/2015JF003647, 2016.

Delannay, R., Valance, A., Mangeney, A., Roche, O., and Richard, P.: Granular and particle-laden flows: from laboratory experiments to field observations, J. Phys. D. Appl. Phys., 50, 053001, https://doi.org/10.1088/1361-6463/50/5/053001, 2017.

Deparis, J., Jongmans, D., Cotton, F., Baillet, L., Thouvenot, F., and Hantz, D.: Analysis of Rock-Fall and Rock-Fall Avalanche Seismograms in the French Alps, B. Seismol. Soc. Am., 98, 17811796, https://doi.org/10.1785/0120070082, 2008.

Department of Earth and Environmental Sciences, Geophysical Observatory, University of Munchen: BayernNetz, International Federation of Digital Seismograph Networks, Other/Seismic Network, https://doi.org/10.7914/SN/BW, 2001.

Ekström, G. and Stark, C. P.: Simple scaling of catastrophic landslide dynamics, Science, 339, 1416-1419, https://doi.org/10.1126/science.1232887, 2013.

Farin, M., Mangeney, A., de Rosny, J., Toussaint, R., SainteMarie, J., and Shapiro, N. M.: Experimental validation of theoretical methods to estimate the energy radiated by elastic waves during an impact, J. Sound Vib., 362, 176-202, https://doi.org/10.1016/j.jsv.2015.10.003, 2016. 
Feng, Z.: The seismic signatures of the 2009 Shiaolin landslide in Taiwan, Nat. Hazards Earth Syst. Sci., 11, 1559-1569, https://doi.org/10.5194/nhess-11-1559-2011, 2011.

Fuchs, F., Kolínský, P., Gröschl, G., Apoloner, M.-T., Qorbani, E., Schneider, F., and Bokelmann, G.: Site selection for a countrywide temporary network in Austria: noise analysis and preliminary performance, Adv. Geosci., 41, 25-33, https://doi.org/10.5194/adgeo-41-25-2015, 2015.

Fuchs, F., Kolínský, P., Gröschl, G., Bokelmann, G., and the AlpArray Working Group: AlpArray in Austria and Slovakia: technical realization, site description and noise characterization, Adv. Geosci., 43, 1-13, https://doi.org/10.5194/adgeo-431-2016, 2016.

Geological Survey-Provincia Autonoma di Trento: Trentino Seismic Network, International Federation of Digital Seismograph Networks, https://doi.org/10.7914/SN/ST, 1981.

Gualtieri, L. and Ekström, G.: Seismic Reconstruction of the 2012 Palisades Rockfall Using the Analytical Solution to Lamb's Problem, B. Seismol. Soc. Am., 107, 63-71, https://doi.org/10.1785/0120160238, 2017.

Hammer, C., Fäh, D., and Ohrnberger, M.: Automatic detection of wet-snow avalanche seismic signals, Nat. Hazards, 86, 601-618, https://doi.org/10.1007/s11069-016-2707-0, 2017.

Hausmann, H., Hoyer, S., Schurr, B., Bruckl, E., Houseman, G., and Stuart, G.: New seismic data improve earthquake location in the Vienna Basin area, Austria, Austrian J. Earth Sci., 103, 2-14, 2010.

Havskov, J. and Ottemoller, L.: SeisAn Earthquake analysis software, Seismol. Res. Lett., 70, 532-534, https://doi.org/10.1785/gssrl.70.5.532, 1999.

Heimann, S., Matos, C., Cesca, S., Rio, I., and Custodia, S.: Lassie: A versatile tool to detect and locate seismic activity, in preparation, Note: interested users to preview Lassie can write to: sebastian.heimann@gfz-potsdam.de, 2018.

Helmstetter, A. and Garambois, S.: Seismic monitoring of Sechilienne rockslide (French Alps): Analysis of seismic signals and their correlation with rainfalls, J. Geophys. Res., 115, F03016, https://doi.org/10.1029/2009JF001532, 2010.

Hetenyi, G., Molinari, I., Clinton, J., Bokelmann, G., Bondar, I., Crawford, W. C., Dessa, J.-X., Doubre, C., Friederich, W., Fuchs, F., Giardini, D., Graczer, Z., Handy, M. R., Herak, M., Jia, Y., Kissling, E., Kopp, H., Korn, M., Margheriti, L., Meier, T., Mucciarelli, M., Paul, A., Pesaresi, D., Piromallo, C., Plenefisch, T., Plomerova, J., Ritter, J., Rumpker, G., Sipka, V., Spallarossa, D., Thomas, C., Tilmann, F., Wassermann, J., Weber, M., Weber, Z., Wesztergom, V., Zivcic, M., the AlpArray Seismic Network Team, the AlpArray OBS Cruise Crew, and the AlpArray Working Group: The AlpArray Seismic Network: A LargeScale European Experiment to Image the Alpine Orogen, Surv. Geophys., 39, 1009-1033, https://doi.org/10.1007/s10712-0189472-4, 2018.

Hibert, C., Mangeney, A., Grandjean, G., and Shapiro, N. M.: Slope instabilities in Dolomieu crater, Reunion Island: From seismic signals to rockfall characteristics, J. Geophys. Res., 116, F04032, https://doi.org/10.1029/2011JF002038, 2011.

Hibert, C., Mangeney, A., Grandjean, G., Baillard, C., Rivet, D., Shapiro, N. M., Satriano, C., Maggi, A., Boissier, P., Ferrazzini, V., and Crawford, W.: Automated identification, location, and volume estimation of rockfalls at Piton de la
Fournaise volcano, J. Geophys. Res.-Earth, 119, 1082-1105, https://doi.org/10.1002/2013JF002970, 2014a.

Hibert, C., Ekström, G., and Stark, C. P.: Dynamics of the Bingham Canyon Mine landslides from seismic signal analysis, Geophys. Res. Lett., 41, 4535-4541, https://doi.org/10.1002/2014GL060592, 2014b.

Hibert, C., Malet, J.-P., Bourrier, F., Provost, F., Berger, F., Bornemann, P., Tardif, P., and Mermin, E.: Single-block rockfall dynamics inferred from seismic signal analysis, Earth Surf. Dynam., 5, 283-292, https://doi.org/10.5194/esurf-5-283-2017, 2017a.

Hibert, C., Ekström, G., and Stark, C. P.: The relationship between bulk-mass momentum and short-period seismic radiation in catastrophic landslides, J. Geophys. Res.-Earth, 122, 12011215, https://doi.org/10.1002/2016JF004027, 2017b.

Hibert, C., Michea, D., Provost, F., Malet, J.-P., and Geertsema, M.: 20 years of landslide activity in Alaska from automated machinelearning based seismic detection, Geophysical Research Abstracts, EGU General Assembly 2018, 20, EGU2018-8595-1, 2018.

Husen, S., Kissling, E., Deichmann, N., Wiemer, S., Giardini, D., and Baer, M.: Probabilistic earthquake location in complex threedimensional velocity models: Application to Switzerland, J. Geophys. Res., 108, 2077, https://doi.org/10.1029/2002JB001778, 2003.

INGV Seismological Data Centre: Rete Sismica Nazionale (RSN), Istituto Nazionale di Geofisica e Vulcanologia (INGV), Italy, https://doi.org/10.13127/SD/X0FXnH7QfY, 1997.

Institut de Physique du Globe de Paris (IPGP) \& Ecole et Observatoire des Sciences de la Terre de Strasbourg (EOST): GEOSCOPE, French Global Network of broad band seismic stations, Institut de Physique du Globe de Paris (IPGP), https://doi.org/10.18715/GEOSCOPE.G, 1982.

Krischer, L., Megies, T., Barsch, R., Beyreuther, M., Lecocq, T., Caudron, C., and Wassermann, J.: ObsPy: a bridge for seismology into the scientific Python ecosystem, Computational Science \& Discovery, 8, 014003, https://doi.org/10.1088/17494699/8/1/014003, 2015.

Küperkoch, L., Meier, T., Brüstle, A., Lee, J., Friederich, W., and working group, E.: Automated determination of $\mathrm{S}$ phase arrival times using autoregressive prediction: application to local and regional distances, Geophys. J. Int., 188, 687-702, https://doi.org/10.1111/j.1365-246X.2011.05292.x, 2012.

Lacroix, P., Grasso, J.-R., Roulle, J., Giraud, G., Goetz, D., Morin, S., and Helmstetter, A.: Monitoring of snow avalanches using a seismic array: Location, speed estimation, and relationships to meteorological variables, J. Geophys. Res., 117, F01034, https://doi.org/10.1029/2011JF002106, 2012.

Levy, C., Mangeney, A., Bonilla, F., Hibert, C., Calder, E. S., and Smith, P. J.: Friction weakening in granular flows deduced from seismic records at the Soufrière Hills Volcano, Montserrat, J. Geophys. Res.-Sol. Ea., 120, 7536-7557, https://doi.org/10.1002/2015JB012151, 2015.

Lima, P., Steger, S., Glade, T., Tilch, N., Schwarz, L., and Kociu, A.: Landslide Susceptibility Mapping at National Scale: A First Attempt for Austria, in: Advancing Culture of Living with Landslides, edited by: Mikos, M., Tiwari, B., Yin, Y., and Sassa, K., WLF 2017, Springer, Cham, https://doi.org/10.1007/978-3-31953498-5_107, 2017. 
Loew, S., Gschwind, S., Gischig, V., Keller-Signer, A., and Valenti, G.: Monitoring and early warning of the 2012 Preonzo catastrophic rockslope failure, Landslides, 14, 141-154, https://doi.org/10.1007/s10346-016-0701-y, 2017.

Lomax, A., Satriano, C., and Vassallo, M.: Automatic Picker Developments and Optimization: FilterPicker - a Robust, Broadband Picker for Real-Time Seismic Monitoring and Earthquake Early Warning, Seismol. Res. Lett., 83, 531-540, https://doi.org/10.1785/gssrl.83.3.531, 2012.

Lopez Comino, J. A., Heimann, S., Cesca, S., Milkereit, C., Dahm, T., and Zang, A.: Automated Full Waveform Detection and Location Algorithm of Acoustic Emissions from Hydraulic Fracturing Experiment, Procedia Engineer., 191, 697702, https://doi.org/10.1016/j.proeng.2017.05.234, 2017.

Lucas, A., Mangeney, A., and Ampuero, J. P.: Frictional velocityweakening in landslides on Earth and on other planetary bodies, Nat. Commun., 5, 3417, https://doi.org/10.1038/ncomms4417, 2014.

Maceira, M., Rowe, C. A., Beroza, G., and Anderson, D.: Identification of low-frequency earthquakes in non-volcanic tremor using the subspace detector method, Geophys. Res. Lett., 37, L06303, https://doi.org/10.1029/2009GL041876, 2010.

Maggi, A., Ferrazzini, V., Hibert, C., Beauducel, F., Boissier, P., and Amemoutou, A.: Implementation of a Multistation Approach for Automated Event Classification at Piton de la Fournaise Volcano, Seismol. Res. Lett., 88, 878-891, https://doi.org/10.1785/0220160189, 2017.

Manconi, A., Picozzi, M., Coviello, V., de Santis, F., and Elia, L.: Real-time detection, location, and characterization of rockslides using broadband regional seismic networks, Geophys. Res. Lett., 43, 6960-6967, https://doi.org/10.1002/2016GL069572, 2016.

MedNet project partner institutions: Mediterranean Very Broadband Seismographic Network (MedNet), Istituto Nazionale di Geofisica e Vulcanologia (INGV), Italy, https://doi.org/10.13127/SD/fBBBtDtd6q, 1988.

Moore, J. R., Pankow, K. L., Ford, S. R., Koper, K. D., Hale, J. M., Aaron, J., and Larsen, C. F.: Dynamics of the Bingham Canyon rock avalanches (Utah, USA) resolved from topographic, seismic, and infrasound data, J. Geophys. Res.-Earth, 122, 615-640, https://doi.org/10.1002/2016JF004036, 2017.

Moretti, L., Mangeney, A., Capdeville, Y., Stutzmann, E., Huggel, C., Schneider, D., and Bouchut, F.: Numerical modeling of the Mount Steller landslide flow history and of the generated long period seismic waves, Geophys. Res. Lett., 39, L16402, https://doi.org/10.1029/2012GL052511, 2012.

Moretti, L., Allstadt, K., Mangeney, A., Capdeville, Y., Stutzmann, E., and Bouchut, F.: Numerical modeling of the Mount Meager landslide constrained by its force history derived from seismic data, J. Geophys. Res.-Sol. Ea., 120, 2579-2599, https://doi.org/10.1002/2014JB011426, 2015.

OGS (Istituto Nazionale di Oceanografia e di Geofisica Sperimentale) and University of Trieste: North-East Italy Broadband Network, International Federation of Digital Seismograph Networks, https://doi.org/10.7914/SN/NI, 2002.

OGS (Istituto Nazionale di Oceanografia e di Geofisica Sperimentale): North-East Italy Seismic Network, International Federation of Digital Seismograph Networks, https://doi.org/10.7914/SN/OX, 2016.
Petschko, H., Brenning, A., Bell, R., Goetz, J., and Glade, T.: Assessing the quality of landslide susceptibility maps - case study Lower Austria, Nat. Hazards Earth Syst. Sci., 14, 95-118, https://doi.org/10.5194/nhess-14-95-2014, 2014.

Provost, F., Hibert, C., and Malet, J.-P.: Automatic classification of endogenous landslide seismicity using the Random Forest supervised classifier, Geophys. Res. Lett., 44, 113-120, https://doi.org/10.1002/2016g1070709, 2017.

RESIF: RESIF-RLBP French Broad-band network, RESIF-RAP strong motion network and other seismic stations in metropolitan France, RESIF - Reseau sismologique \& geodesique francais, https://doi.org/10.15778/RESIF.FR, 1995.

Roth, D. L., Finnegan, N. J., Brodsky, E. E., Rickenmann, D., Turowski, J. M., Badoux, A., and Gimbert, F.: Bed load transport and boundary roughness changes as competing causes of hysteresis in the relationship between river discharge and seismic amplitude recorded near a steep mountain stream, J. Geophys. Res.-Earth, 122, 1182-1200, https://doi.org/10.1002/2016JF004062, 2017.

Schmandt, B., Aster, R. C., Scherler, D., Tsai, V. C., and Karlstrom, K.: Multiple fluvial processes detected by riverside seismic and infrasound monitoring of a controlled flood in the Grand Canyon, Geophys. Res. Lett., 40, 4858-4863, https://doi.org/10.1002/grl.50953, 2013.

Slovenian Environment Agency: Trentino Seismic Network, International Federation of Digital Seismograph Networks, https://doi.org/10.7914/SN/SL, 2001.

Soubestre, J., Shapiro, N. M., Seydoux, L., de Rosny, J., Droznin, D. V., Droznina, S. Y., Senyukov, S. L., and Gordeev, E. I.: Network-Based Detection and Classification of Seismovolcanic Tremors: Example From the Klyuchevskoy Volcanic Group in Kamchatka, J. Geophys. Res.-Sol. Ea., 123, 564-582, https://doi.org/10.1002/2017JB014726, 2018.

Swiss Seismological Service (SED) at ETH Zurich: National Seismic Networks of Switzerland, ETH Zurich, https://doi.org/10.12686/sed/networks/ch, 1983.

The ObsPy Development Team: (27 February 2017) ObsPy 1.0.3, Zenodo, https://doi.org/10.5281/zenodo.165134, 2017.

Trnkoczy, A.: Understanding and parameter setting of STA/LTA trigger algorithm, in: New Manual of Seismological Observatory Practice 2 (NMSOP2), edited by: Bormann, P., 1-20, Deutsches GeoForschungsZentrum GFZ, Potsdam, https://doi.org/10.2312/GFZ.NMSOP-2_ch4, 2012.

University of Genova: Regional Seismic Network of North Western Italy, International Federation of Digital Seismograph Networks, https://doi.org/10.7914/SN/GU, 1967.

van Herwijnen, A. and Schweizer, J.: Monitoring avalanche activity using a seismic sensor, Cold Reg. Sci. Technol., 69, 165-176, https://doi.org/10.1016/j.coldregions.2011.06.008, 2011.

van Herwijnen, A., Heck, M., and Schweizer, J.: Forecasting snow avalanches using avalanche activity data obtained through seismic monitoring, Cold Reg. Sci. Technol., 132, 68-80, https://doi.org/10.1016/j.coldregions.2016.09.014, 2016.

Walter, F., Burtin, A., McArdell, B. W., Hovius, N., Weder, B., and Turowski, J. M.: Testing seismic amplitude source location for fast debris-flow detection at Illgraben, Switzerland, Nat. Hazards Earth Syst. Sci., 17, 939-955, https://doi.org/10.5194/nhess-17939-2017, 2017.

Walter, M., Schwaderer, U., and Joswig, M.: Seismic monitoring of precursory fracture signals from a destructive rockfall in the Vo- 
rarlberg Alps, Austria, Nat. Hazards Earth Syst. Sci., 12, 35453555, https://doi.org/10.5194/nhess-12-3545-2012, 2012.

Wang, N., Shen, Y., Flinders, A., and Zhang, W.: Accurate source location from waves scattered by surface topography, J. Geophys. Res.-Sol. Ea., 121, 4538-4552, https://doi.org/10.1002/2016JB012814, 2016.
Ye, S., Ansorge, J., Kissling, E., and Mueller, S.: Crustal structure beneath the eastern Swiss Alps derived from seismic refraction data, Tectonophysics, 242, 199-221, https://doi.org/10.1016/0040-1951(94)00209-R, 1995. 